\title{
Introducing Collaborative Teaching into Elective Courses Across an Engineering University: Effect of Teacher's Characteristics on Student Evaluations of Teaching
}

\author{
Rong-Jun Pan \\ Inst. of Application of Nanosci. \& Nanotechnol. \\ Guangxi University of Science and Technology \\ Liuzhou, China \\ Xue-Wen Feng \\ Lushan College \\ Guangxi University of Science and Technology \\ Liuzhou, China
}

\author{
Xiao-Jin Feng \\ Department of Education Administration \\ Guangxi University of Science and Technology \\ Liuzhou, China \\ Hui-Qin $\mathrm{Wu}$ \\ Civil Engineering College \\ Guangxi University of Science and Technology \\ Liuzhou, China
}

\begin{abstract}
Collaborative teaching can benefit the students with diverse learning characteristics a lot to access and achieve high academic performances. Student evaluations of teaching is widely used as a metric to estimate instructor effectiveness. To estimate the effects of different teachers' characteristics on teaching performance, collaborative teaching was adopted in elective courses in the last several years across an engineering university in this study. About 4000 college students involved in the progress were surveyed to determine the impact of teacher's characteristics on their evaluations of teaching. The results we obtained demonstrated that gender exerts slight influences on the student evaluation of teaching, however, age, academic rank, and experience affect the evaluation greatly. Highly positive responses on the survey in the experiment suggest continuing and expanding the collaborative teaching model in elective courses.
\end{abstract}

Keywords-Collaborative teaching; Elective courses; Teachers' characteristics; Student evaluations of teaching

\section{INTRODUCTION}

The courses reform of higher education can bridge the gap of traditional education and modern knowledge development [1]. Elective courses are classes that a student can take which are not specifically required to graduate or to fulfill a degree [2]. In colleges and universities, elective courses give students the chance to take classes outside of a prescribed plan of coursework, which lets students pursue other interests they may have. An elective course can either be an upgrade of a mandatory course to a higher educational level, or it can be a course with a subject the students has not been taught before, which means it is essential to expand students' knowledge and skills by taking elective course, especially for those with

Supported by the Teaching Reform Project of Guangxi Higher Education in New Century (2012JGA179) and the Project of Innovation in Guangxi Postgraduate Education (JGY2015120) diverse learning characteristics [3]. In comparison with the compulsory courses, it features flexibility, variety, and openness, which makes it being of challenges in system design, content selection, teaching organization, and course evaluations Due to such advantages, elective courses are extensively delivered worldwide. Although, college and university courses currently consist of compulsory courses and elective courses in China, even the whole world, the elective courses are delivered only according to the teachers own plan, instead of systematic top-level design on both central administration and school level Therefore, almost all elective courses are lack of multidisciplinary combination, resulting in poor relationships between compulsory and elective courses, hence restraining the positivity of the course system [1-3]. Meanwhile, each teacher works more or less independently, which hinders the positive role of elective courses in constructing the mutual connections between the courses. Thus, it is imperative to reform the elective courses.

Collaborative teaching, also known as team teaching, is originated in 1980's. Over the past several decades, collaborative teaching efforts have strengthened and benefited teaching experience in several ways [4]. Collaborative teaching is defined as "any academic experience in which two professors work together in designing and teaching a course that itself uses group teaching techniques" [5] or "two or more people sharing responsibility for educating some or all of the students in a classroom based on the same teaching theme" [6]. Vasquez-Montilla et al. illuminated how collaborating teaching works [7]. The program was specifically designed to integrate concepts and skills from four diverse disciplines. Each member of the teaching team, therefore, brought multiple perspectives on philosophy, pedagogy, and content knowledge as well as 
their individual personal styles of teaching while conducting their own teaching. Collaborative teaching is an unceasing enhancement and improvement, during which the teaching members can explore kinds of approaches and co-improve so as to achieve the same goal [8].

Most educators belief that high performance teaching contributes to efficient learning. As effective learning depends on the part of the learner whether one is active and highly motivated, student evaluations of teaching are used as a metric to estimate the teaching effectiveness [9]. Moreover, the teaching style may significantly affect the student evaluations of teaching. In order to adjust the teaching style so as to match or suit the students, it is can only be achieved when universities are aware of students learning style and its impact on academic performance. Student evaluation of teaching is currently one of the teaching quality evaluation and guarantee systems, which is an activity that universities organize the related students to evaluate the teaching quality in scientific evaluation theories [10]. It plays a greatly positive role in teaching reform and improving teaching quality. As student evaluations are of reliability, long-term stability, and comprehensiveness, it has served as a metric and the fundamental system to guarantee the quality of teaching [11]. In practice, it is used to evaluate instructor effectiveness and are used to make promotion, tenure, and retention decisions for faculty [9-12]. It has demonstrated that the teachers' characteristics exert strongly influence on student evaluations of teaching [13].

In the article, a teaching team were organized to conduct an elective course of Functional Materials for 7 years, namely 14 semesters. About 4000 college students involved in the progress were surveyed to determine the impact of teacher characteristics on their evaluations of teaching so as to guide the teaching reform of elective courses in an engineering university.

\section{METHOD AND RESULTS}

\section{A. Method}

Many studies have identified the influence of background characteristics on student evaluations of teaching markedly, one of which is teachers' characteristics. As some studies have demonstrated that the warmth or charisma and ethnicity exert influences on the metric $[2,14]$, hence herein, we focused on the following three objective demographic characteristics of gender, experience, and academic rank. Therefore, teachers' characteristics of gender, experience, age, and academic rank, are applied to study the evaluations of teaching in the present study.

Thus, we propose the following hypotheses for experience:

All the gender, experience and academic rank affect the student evaluations of teaching.

The experience is the key factor that affects the student evaluations of teaching.

The data for the study comes from an engineering university ranged for 7 years, 14 semesters. Data were collected for 100 elective courses taught during that time, among which 540 male teachers and 352 female, as illustrated in Table 1. The evaluation was conducted according to the following formula:

$$
\mathrm{T}=\sum_{i=1}^{n} \frac{\mathrm{Y}_{i} \log \mathrm{Y}_{i}}{\mathrm{P}_{i}}
$$

Where $\mathrm{T}$ is Theil index, $\mathrm{i}$ represents the teacher, Yi is the proportion of student evaluation teaching, $\mathrm{Pi}$ is the proportion of the classes that Teacher $i$ conducted. A great $T$ means a great difference of student evaluations of teaching scores.

TABLE I VARIABLE AND DEFINITION OF INDICATOR

\begin{tabular}{l|l}
\hline Influence factor & indicator \\
\hline Gender & Male, female \\
\hline Age & $26 \sim 30,31 \sim 35,36 \sim 40,41 \sim 45,46 \sim 50,51 \sim 55$, \\
& $56 \sim 60$, above 60 \\
\hline Academic rank & Full professor, associate professor, lecturer \\
\hline Experience & $\begin{array}{l}\text { Engaged for 1 2 year, 3 5 year, 5 10year, } \\
\text { above 10 year }\end{array}$ \\
\hline
\end{tabular}

\section{B. Results}

The results are shown in Table 2. As for gender, some researchers consider that male teachers had higher student evaluation of teaching than their female counterparts $[15,16]$, while the others argue that female teachers who interacted more with students or self-supported themselves as "warm" received higher competency ratings [14, 17]. And some consider that there was no or only an insignificant effect of instructor gender on student evaluation of teaching [18-20]. Considering a combined student evaluation of teaching obtained from female and male students, as demonstrated in Table 2, the gender of teacher exerts slight influences on the student evaluation of teaching, which is in accordance with the previous studies of References [18-20].

Experience is a demographic factor that might affect the teaching performance and thus the student evaluation of teaching. As demonstrated in previous work, experience does improve the student evaluation of teaching. Ratz reported a $6 \%$ increase in student evaluation of teaching score if a course has been taught previously by the teacher [21]. It was found that teachers have low scores for their first two years of teaching, which is in accordance with the previous study of Ref. [22]. After the initial semester, teacher's scores significantly improved because most new teachers gained their teaching experiences during the initial semester instead of receiving their official training of teaching theories during their undergraduate and graduate periods [23]. In addition to teaching experience, some studies examined the role of age. Obviously, these two variables are of high correlation-one usually gains experiences as it ages. Therefore, as teaching experience generally improves student evaluation of teaching scores, the scores increase as they grow gradually. However, an opposite conclusion was presented in the study-older teachers (up to age 55) had lower scores [15]. Clayson evaluated the effects of age on a more granular level and found that as instructor age increases, scores for knowledge improve [24]. However, in the late stage of teaching career, lower scores presented, in which the lower scores might be caused by their less efforts spent on teaching, boredom and apathy for teaching. 
Therefore, an improvement in teaching is urgently imperative for those over 50 although they may be skilled in teaching activity.

Of course, it is reasonable that teachers with more excellent skills to help students learn better are more likely to get promoted and therefore have higher academic rank, that is, a teacher with higher academic rank would receive higher student evaluations of teaching. Therefore, commonly considered to be a work requiring professional skills, the teaching skills would increase with the age. Thus, as illustrated in Table II, higher academic rank showed great influences on the evaluations, as higher academic rank means newly knowledge, wide teaching views, and excellent teaching methods originated from the universities and teachers one graduated. As with experience, it is possible that teachers who favor student learning are more likely to get promoted and therefore should have higher scores. Assistant professors may focus more on research, while full professors may be better equipped to excel at both teaching and research [25]. Spooren found that associate professors and lecturers received significantly lower scores than did full professors [26]. However, some studies of academic rank have shown no differences among differing rank [27, 28]. According to Goldberg and Callahan, there is a perception that higher grades lead to higher scores and that not-tenure-track faculty may give higher grades and, therefore, gains higher student evaluations of teaching [29].

Additionally, because the teaching is conducted by members with individual differences such as personality, popularity, lecture fluency, non verbal behavior and attractiveness, the Dr. Fox Effect may also exert certain influences on the evaluations accordingly [30,31].

TABLE II THE LINEAR-REGRESSION ANALYSIS OF FACTORS THAT INFLUENCE THE STUDENT EVALUATIONS OF TEACHING

\begin{tabular}{l|l|l|l}
\hline Index & Variable & B & Beta \\
\hline \multirow{3}{*}{ gender } & Male & -.59 & -.14 \\
\cline { 2 - 4 } & Female & -.62 & -.18 \\
\hline \multirow{4}{*}{ age } & $36-40$ & -.599 & -.160 \\
\cline { 2 - 4 } & $41-45$ & -.966 & -.234 \\
\cline { 2 - 4 } & $46-50$ & -.946 & -.191 \\
\cline { 2 - 4 } & $51-55$ & -1.520 & -.264 \\
\cline { 2 - 4 } & $56-60$ & -1.301 & -.161 \\
\hline \multirow{4}{*}{ Professional title } & Professor & .553 & .124 \\
\cline { 2 - 4 } & Associate professor & .198 & .058 \\
\cline { 2 - 4 } & Leaturer & .042 & .012 \\
\hline \multirow{4}{*}{ Experience/ year } & $1-2$ & .21 & .025 \\
\cline { 2 - 4 } & $3-10$ & .48 & .063 \\
\cline { 2 - 4 } & $>10$ & .76 & .14 \\
\hline
\end{tabular}

\section{CONCLUSIONS}

The results revealed that student evaluations of teaching are affected by several factors, which presents the students' satisfaction on teaching offered by certain teacher. Firstly, the age and academic rank exert great influences on student evaluations of teaching. As an activity of skill, teaching experience plays an important role during the whole teaching process. When instructor is well equipped with teaching skills, one should widen its knowledge vision, and thus resulting in higher evaluations. Conversely, the student evaluations of teaching would be lower.

Teachers are the soul of a college and university, the mission of instructors is to provide students with excellent quality education. Universities should effectively strengthen the teaching staff construction and improve their teaching ability so as to offer more excellent teaching. Student evaluations of teaching is an important metric to estimate teachers' teaching level and ability. Only when teachers are aware of the importance and the necessity of teaching evaluations, can one self-examine ones teaching activity hence improve the teaching ability. Moreover, the occupation boredom of teachers is appeared in the study, longer teaching experience might lead to lower teaching evaluation scores as one despises the organization and process of teaching.

\section{POLICY SUGGESTIONS}

As for collaborative teaching, positive effectiveness are presented while conducting elective courses across an engineering university. The results suggested that student evaluations of teaching are affected by teacher's characteristics. Therefore, the following suggestions might be put forward.

Firstly, collaborative teaching is an important approach to enhance the teachers' teaching ability. The reform of new curriculum not only proposes higher goals for students' study, but also puts forward new demands for the setting of courses and teachers' teaching ability. Traditionally, teachers used to work independently, lacking cooperation with other teachers, even those in the same fields. As for collaborative teaching, the team members work together in curriculum designing and teaching, sharing the responsibility, exploring the teaching methods, and accomplishing the same goals. By this coimproving way, all kinds of teaching skills can be integrated to serve the teaching. That is why positive responses could be statistically achieved while collaborative teaching is introduced into teaching, suggesting that collaborative teaching be continued and expanded.

Secondly, student evaluations of teaching are a widely employed metric to assess teaching performances and for evaluating the teachers for promotion, pay, tenure, and hiring decisions. As student evaluations of teaching become increasingly available for educational administrators and teachers, student evaluation of teaching should be focused on reasonably for both the administrators and instructors for selfassessment and self-improvement. Only in this way, can one improves itself effectively. As elective courses lack of systematic top-level design on both central administration and school level, student evaluation of teaching can also serve as an important probe to better the course design and hence highlight the positive role of elective courses and the relationships between compulsory and elective courses.

Thirdly, teaching staff construction should be continually enhanced so as to improve the teaching skills. As demonstrated in the study, teaching is not only affected by one's academic rank, age, and professional title. That is why the evaluation goes up and down as the age increases, which might be caused by the professional burnout. As the burnout is traditionally induced by the age of teaching, the title of technical post, the 
attitude of teaching, and gender. Therefore, teaching quality monitoring should be strengthened for teaching evaluation and promotion. Teachers should also be encouraged to explore teaching approaches and keep knowledge up to date, and hence providing better teaching to feed the students.

\section{REFERENCES}

[1] J. Y.Y. Kwan, J. Nyhof-Young, P. Catton, M. E. Giuliani, "Mapping the Future: Towards oncology curriculum reform in undergraduate medical education at a Canadian medical school," Int. J. Radiation Oncol Biol. Phys., 91(3) (2015) 669-677.

[2] F. Alkan, E. Erdem, 'The effect of elective courses on candidate teachers' level of social skills," Procedia Social and Behavioral Sci., 15(2011) 3451-3455.

[3] O. Sorias, "Sosyal Beceriler ve degerlendirme yotemleri,' Psikoloji Dergisi, 5(1986) 25-26.

[4] K. Chiasson, J. A. Yearwood, G. Olsen, "The best of both worlds: combining ECE and ECSE philosophies and best practices through a coteaching model," Journal of Early Childhood Teacher Education, 27(3)(2006) 303-312.

[5] R. Robinson, R. Schaible, "Collaborative teaching: reaping the benefits," College Teaching, 43(2) (1995) 57-60.

[6] R. Villa, J. Thousand, A. Nevin, A guide to co-teaching: Practical tips for facilitating student learning (2nd Ed.), Thousand Oaks, 2008.

[7] E. Vasquez-Montilla, C. Spillman, E. Elliott, A. McGonney, "Coteaching in teacher education: expectations, inspirations and limitations," Florida Educational Leadership, 7(2) (2007) 47-51.

[8] E.A. Knackendoffel, S.M. Robinson, D.D. Deshler, J.B. Schumaker, Collaborative problem salving, Lawrence, 1992.

[9] L. Langbein, "Management by results: Student evaluation of faculty teaching and the mis-measurement of performance," Economics of Education Review, 27(4)(2008) 417-428.

[10] M. Lei, "Explorations and policies to improve student evaluation of teaching in universities," Higher Education Exploration, 1(2005) 50-53.

[11] D. R. Bie, F. Meng, "Improvements of student evaluation of teaching and higher education quality guarantee system," Higher Education Exploration, 12(2007) 77-83.

[12] H. K. Wachtel, "Student evaluation of college teaching effectiveness: A brief review,' Assessment \& Evaluation in Higher Education, 23(2) (1998) 191-212.

[13] C. Wang, "Student evaluation and enlightenment of American colleges," J. Nantong Teachers College (Social Science Ed.), 18(1) (2000)126-127. (in Chinese)

[14] S. K. Bennett, "Student perceptions of and expectations for male and female instructors: Evidence relating to the question of gender bias in teaching evaluation,” J. Edu. Psychol., 74(2)(1982) 170-179.
[15] M. A. McPherson, R. T. Jewell, "Leveling the playing field: Should student evaluation scores be adjusted?" Social Science Quarterly, 88(3)(2007) 868-881.

[16] J. Morgan, T. Davies, "Analysis of bias in student evaluations of faculty at an all female Arab university in the Middle East," Learning and Teaching in Higher Education: Gulf Perspectives, 3(2) (2006) 1-20.

[17] A. Statham, L. Richardson, J. A. Cook, Gender and university teaching: A negotiated difference, Albany, 1991.

[18] K. A. Feldman, “College students' views of male and female college teachers: Part II- Evidence from students' evaluations of their classroom teachers," Research in Higher Education, 34(1993) 151-211.

[19] J. A. Centra, N. B. Gaubatz, "Is there gender bias in student evaluations of teaching?" J. Higher Education, 71(1)(2000) 17-33.

[20] G. C. Blackhart, B. M. Peruche, C. N. Dewall, Jr T. E. Joiner, "Factors influencing teaching evaluations in higher education," Teaching of Psychology, 33(1)(2006) 37-39.

[21] H. C. Ratz, "Factors in the evaluation of instructors by students," IEEE Transactions on Education, E-18(3) (1975) 122-127.

[22] J. Ragan, B. Walia, "Differences in student evaluations of principles and other economics courses and the allocation of faculty across courses," J. Economic Education, 41(2010) 335-352.

[23] J. Morgan, T. Davies, "Analysis of bias in student evaluations of faculty at an all female Arab university in the Middle East," Learning and Teaching in Higher Education: Gulf Perspectives, 3(2)(2006) 1-20.

[24] D. E. Clayson, T. F. Frost, M. J. Sheffet, "Grades and the student evaluation of instruction: A test of the reciprocity effect," Academy of Management Learning \& Education, 5(1)(2006) 52-65.

[25] K. A. Feldman, "Research productivity and scholarly accomplishment of college teachers as related to their instructional effectiveness: A review and exploration," Research in Higher Education, 26(3)(1987) 227-298.

[26] P. Spooren, "On the credibility of the judge: A cross-classified multilevel analysis on students' evaluation of teaching,' Studies in Educational Evaluation, 36(4)(2010) 121-131.

[27] L. M. Aleamoni, G. S. Thomas, "Differential relationships of student, instructor, and course characteristics to general and specific items on a course evaluation questionnaire," Teaching of Psychology, 7(4)(1980) 233.

[28] F. Zabaleta, "The use and misuse of student evaluations of teaching," Teach. Higher Education, 12(1) (2007) 55-76.

[29] G. Goldberg, J. Callahan, "Objectivity of student evaluations of instructors," J. Edu. Bus., 66(6) (1991) 377.

[30] D. H. Naftulin, J. E. Ware Jr., F. A. Donnelly, ’The Doctor Fox Lecture: A paradigm of educational seduction," J. Medical Edu., 48 (1973) 630635.

[31] R. Williams, J. Ware, "Validity of student ratings of instruction under different incentive conditions: A further study of the Dr. Fox effect," J. Edu. Psychol., 68 (1976) 48-56. 